\title{
Finite Difference Approximation for Solving Transient Heat Conduction Equation of Copper
}

\author{
Dalal Adnan Maturi, Nujud Makhdhur Alsulami, Eman Salem Alaidarous \\ Department of Mathematics, Faculty of Science, King Abdulaziz University, Jeddah, Saudi Arabia \\ Email:dmaturi@kau.edu.sa, Goody366@gmail.com, ealaidarous@kau.edu.sa
}

How to cite this paper: Maturi, D.A. Alsulami, N.M. and Alaidarous, E.S. (2020) Finite Difference Approximation for Solving Transient Heat Conduction Equation of Copper. Advances in Pure Mathematics, 10, 350-358.

https://doi.org/10.4236/apm.2020.105021

Received: April 14, 2020

Accepted: May 23, 2020

Published: May 26, 2020

Copyright $\odot 2020$ by author(s) and Scientific Research Publishing Inc. This work is licensed under the Creative Commons Attribution International License (CC BY 4.0).

http://creativecommons.org/licenses/by/4.0/

\begin{abstract}
In this paper, a numerical technique is proposed to obtain the solution for transient heat conduction equation of Copper. The copper element is characterized by many characteristics; the most important of which is its high ability to conduct heat and electrical conductivity, in addition to being a flexible and malleable metal that is easy to form without being broken, making it one of the basic minerals that humans have benefited from for thousands of years, it is one of the first minerals. That has been discovered and extracted, and still plays a major role in the development of societies. The obtained solutions are compared with the available exact solutions and the obtained solutions using the finite difference method. The results indicate that the finite difference method is a highly effective method for obtaining approximate solutions for the thermal conductivity equation for copper. It is also clear from the numerical results from copper in the high conductivity of heat and electricity.
\end{abstract}

\section{Keywords}

Finite Difference Approximation, Transient Heat Conduction Equation, Copper, Matlab

\section{Introduction}

William [1] numerical methods for partial differential equations, Jim [2] on the numerical solution of heat conduction problems in two and three space variables, in 1980, Mitchell and Griffiths [3] the finite difference method in partial differential equations. In 2014, Dalal et al. [4] numerical solution of Volterra integral equation of second kind using implicit trapezoidal, Dalal [5] adomian decomposition method of Fredholm, Dalal [6] applications of adomian decomposition method for solving of Fredholm integral equation. In 2016, Dalal [7] adomian decomposition method of solving of Fredholm integral equation of the second 
kind using Matlab. In 2018, Dalal [8] numerical solution of system of three nonlinear Volterra integral equation using implicit trapezoidal. In 2019, Dalal et al. [9] finite difference method for solving heat conduction equation of the Granite. In 2020, Dalal [10] finite difference method for solving heat conduction equation equation of the Brick. In Finite difference methods, the derivatives in the partial differential equation are replaced with finite difference approximations. The domain of the solution $[a, b]$ is divided into $N$ subintervals of equal length $h$, that are defined by $(N+1)$ points called grid points. The length of each subinterval is then $h=(b-a) / N$. Points $a$ and $b$ are the end points, and the rest of the points are the interior points.

We apply the Finite difference approximation method for solve the heat conduction equation of the Copper.

Advantages of using Copper: Copper is used in the manufacture of electrical wires because of its high conductivity of electricity. It is also used in the manufacture of many electrical and electronic devices and devices, such as: transformers, power generators, television, mobile phones, and other devices. Among the most important uses of copper in the electricity sector is its use in telecommunications Where micro wires are made especially for Internet lines related to local networks, in addition to making use of copper in the field of renewable energy, specifically in the manufacture of wind turbines, photovoltaic cells, and other devices related to the technology of renewable energy this.

\section{Finite Difference Method for Heat Conduction Equation}

The linear second order partial differential equation

$$
A u_{x x}+2 B u_{x y}+C u_{y y}+D u_{x}+E u_{y}+F u+G=0
$$

as a parabolic equation if $B^{2}-A C=0$. A parabolic equation holds in an open domain or in a semi-open domain.

Consider a thin homogeneous, insulated bar or a wire of length $l$. Let the bar be located on the $x$-axis on the interval $[0,1]$. See the rod have a source of heat. For example, the rod may be heated at one end or at the middle point or has some source of heat. Give $u(x, t)$ denote the temperature in the rod at any instant of time $t$. The problem is to study the flow of heat in the rod. The partial differential equation governing the flow of heat in the rod is given by the parabolic equation

$$
u_{t}=c^{2} u_{x x}, 0 \leq x \leq l, t>0 .
$$

where $c^{2}$ is a constant and depends on the material properties of the rod.

The heat conduction equation of the Copper

$$
\begin{gathered}
u_{t}=1.14 u_{x x} \\
u(0, t)=u(1, t)=0, \quad \forall t \in\left(0, t_{F}\right) \\
u(x, 0)=u_{0}(x), \quad \forall x \in[0,1],
\end{gathered}
$$

where $t_{F}$ Denotes the terminal time for the model. Here without loss of gene- 
rality, we assume that the spatial domain is $[0,1]$.

At first divide the physical domain $\left(0, t_{F}\right) \times(0,1)$ by $N \times J$ uniform grid points

$$
\begin{aligned}
& t_{n}=n \Delta t, \Delta t=\frac{t_{F}}{N}, n=0,1, \cdots, N, \\
& x_{j}=j \Delta x, \Delta x=\frac{1}{J}, j=0,1, \cdots, J .
\end{aligned}
$$

Then, we denote the approximate solution $u_{j}^{n} \approx u\left(x_{j}, t_{n}\right)$. At an arbitrary point $\left(x_{j}, t_{n}\right)$. To obtain afinite difference scheme, we need to approximate the derivatives in (1) by some finite differences. (Explicit scheme) Substituting

$$
\begin{gathered}
u_{t}\left(x_{j}, t_{n}\right) \approx\left(u_{j}^{n}-u_{j}^{n-1}\right) / \Delta t, \\
u_{x x}\left(x_{j}, t_{n}\right) \approx\left(u_{j+1}^{n}-2 u_{j}^{n}+u_{j-1}^{n}\right) /(\Delta x)^{2},
\end{gathered}
$$

Into (2), another difference scheme for (2) can be constructed as:

$$
\frac{u_{j}^{n}-u_{j}^{n-1}}{\Delta t}=\frac{u_{j+1}^{n}-2 u_{j}^{n}+u_{j-1}^{n}}{(\Delta x)^{2}}, 1 \leq j \leq J-1,1 \leq n \leq N .
$$

\section{Numerical Simulations and Discussion}

1) Example 1. Find the solution of the heat conduction equation of the Copper

$$
\begin{gathered}
u_{t}=1.14 u_{x x}, 0<x<1, t>0 ; \\
u(0, t)=u(1, t)=0, t>0 ; \\
u(x, 0)=40-3 x, 0 \leq x \leq 1 .
\end{gathered}
$$

Applying the finite difference method using Matlab, then the result show as follows.

2) Example 2. Find the solution of the heat conduction equation of the Copper

$$
\begin{gathered}
u_{t}=1.14 u_{x x}, 0<x<1, t>0 ; \\
u(0, t)=u(1, t)=0, t>0 ; \\
u(x, 0)=7 \cos \left(\frac{5}{2} x\right), 0 \leq x \leq 1 .
\end{gathered}
$$

Applying the finite difference method using Matlab, then the result show as follows.

3) Example 3. Find the solution of the heat conduction equation of the Copper

$$
\begin{gathered}
u_{t}=1.14 u_{x x}, 0<x<1, t>0 ; \\
u(0, t)=u(1, t)=0, t>0 ; \\
u(x, 0)=1+\cos (2 \pi x), 0 \leq x \leq 1 .
\end{gathered}
$$

Applying the finite difference method using Matlab, then the result show as follows.

4) Example 4. Find the solution of the heat conduction equation of the Copper

$$
u_{t}=1.14 u_{x x}, 0<x<1, t>0 \text {; }
$$




$$
\begin{gathered}
u(0, t)=u(1, t)=0, t>0 ; \\
u(x, 0)=-\sin (3 \pi x)+\frac{1}{4} \sin (6 \pi x), 0 \leq x \leq 1 .
\end{gathered}
$$

Applying the finite difference method using Matlab, then the result show as follows.

5) Example 5. Find the solution of the heat conduction equation of the Copper

$$
\begin{gathered}
u_{t}=1.14 u_{x x}, 0<x<1, t>0 ; \\
u(0, t)=u(1, t)=0, t>0 ; \\
u(x, 0)=x(1-x), 0 \leq x \leq 1 .
\end{gathered}
$$

Applying the finite difference method using Matlab, then the result show as follows.

6) Example 6. Find the solution of the heat conduction equation of the Copper

$$
\begin{gathered}
u_{t}=1.14 u_{x x}, 0<x<1, t>0 ; \\
u(0, t)=u(1, t)=0, t>0 ; \\
u(x, 0)=\sin x-3 \cos 4 x, 0 \leq x \leq 1 .
\end{gathered}
$$

Applying the finite difference method using Matlab, then the result show as follows.

7) Example 7. Find the solution of the heat conduction equation of the Copper

$$
\begin{gathered}
u_{t}=1.14 u_{x x}, 0<x<1, t>0 ; \\
u(0, t)=u(1, t)=0, t>0 ; \\
u(x, 0)=\sin 2 \pi x-\sin 5 \pi x, 0 \leq x \leq 1 .
\end{gathered}
$$

Applying the finite difference method using Matlab, then the result show as follows.

8) Example 8. Find the solution of the heat conduction equation of the Copper

$$
\begin{gathered}
u_{t}=1.14 u_{x x}, 0<x<1, t>0 ; \\
u(0, t)=u(1, t)=0, t>0 ; \\
u(x, 0)=\sin \pi x, 0 \leq x \leq 1 .
\end{gathered}
$$

Applying the finite difference method using Matlab, then the result show as follows.

9) Example 9. Find the solution of the heat conduction equation of the Copper

$$
\begin{gathered}
u_{t}=1.14 u_{x x}, 0<x<1, t>0 ; \\
u(0, t)=u(1, t)=0, t>0 ; \\
u(x, 0)=2 \sin (\pi x / 2)-\sin \pi x+4 \sin 2 \pi x, 0 \leq x \leq 1 .
\end{gathered}
$$

Applying the finite difference method using Matlab, then the result show as follows.

As we can see from Figures 1-9, the behavior of each transient heat equation of the Copper. Figure 1 shows the temperature distribution of the copper conduction of the conditions 

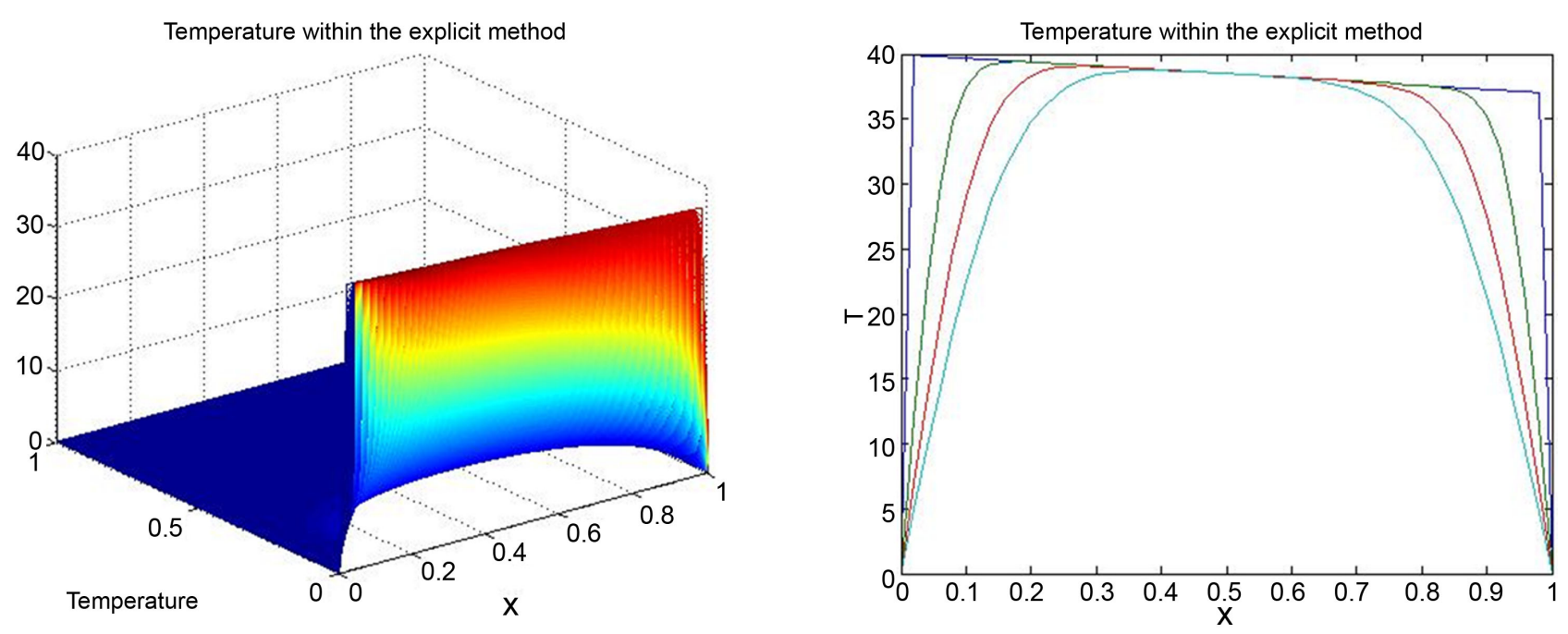

Figure 1. Temperature distributions at several times for the heat conduction of the Copper for example 1.
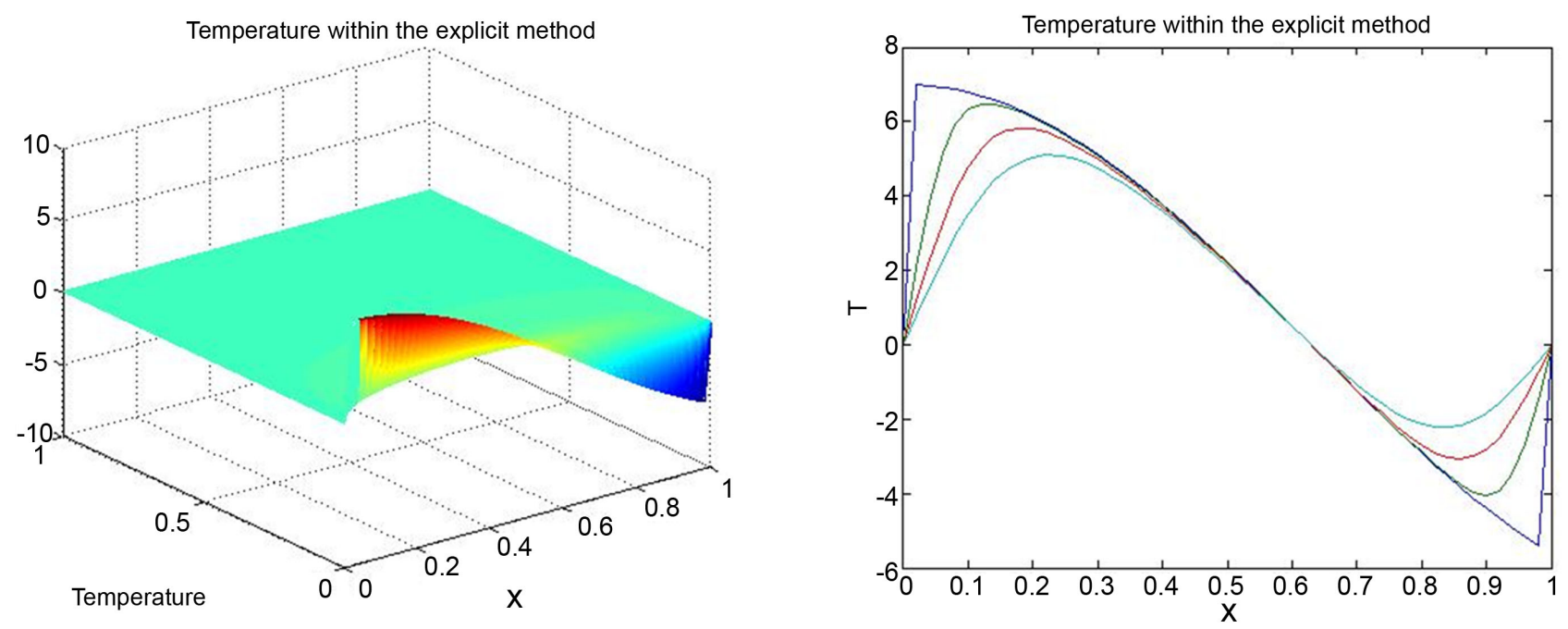

Figure 2. Temperature distributions at several times for the heat conduction of the Copper for example 2.
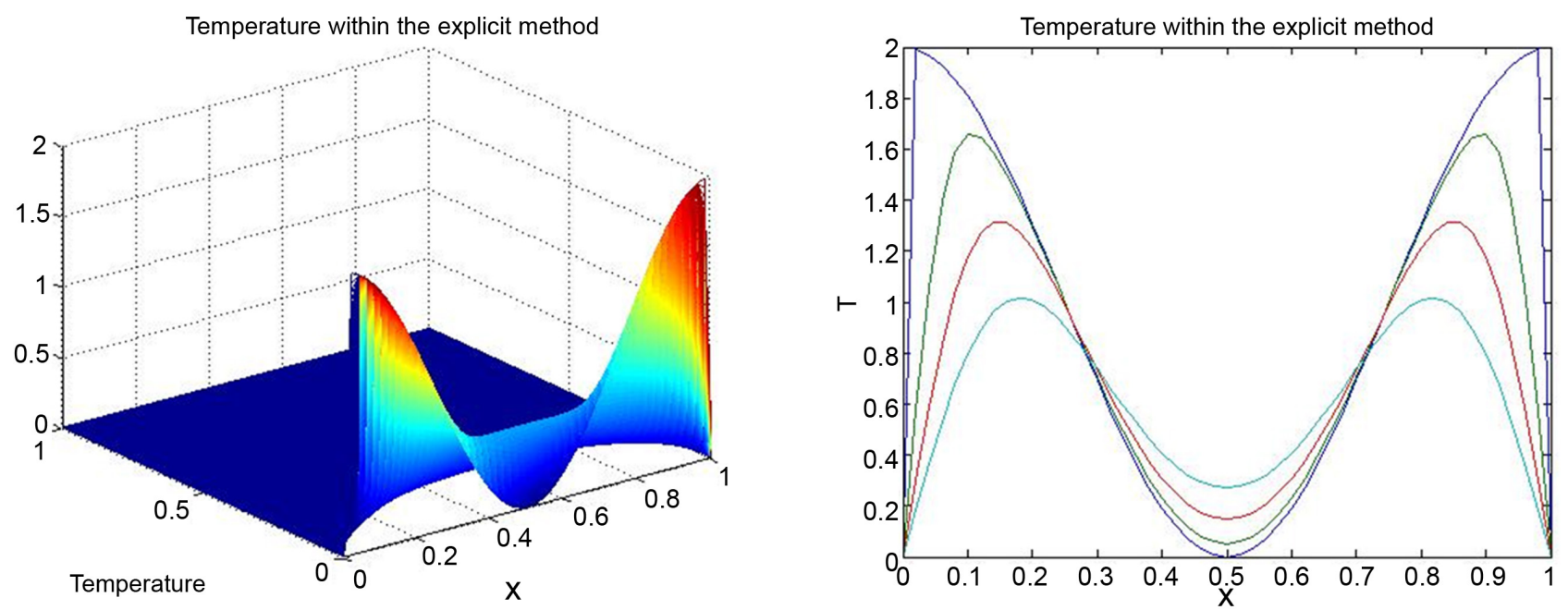

Figure 3. Temperature distributions at several times for the heat conduction of the Copper for example 3. 

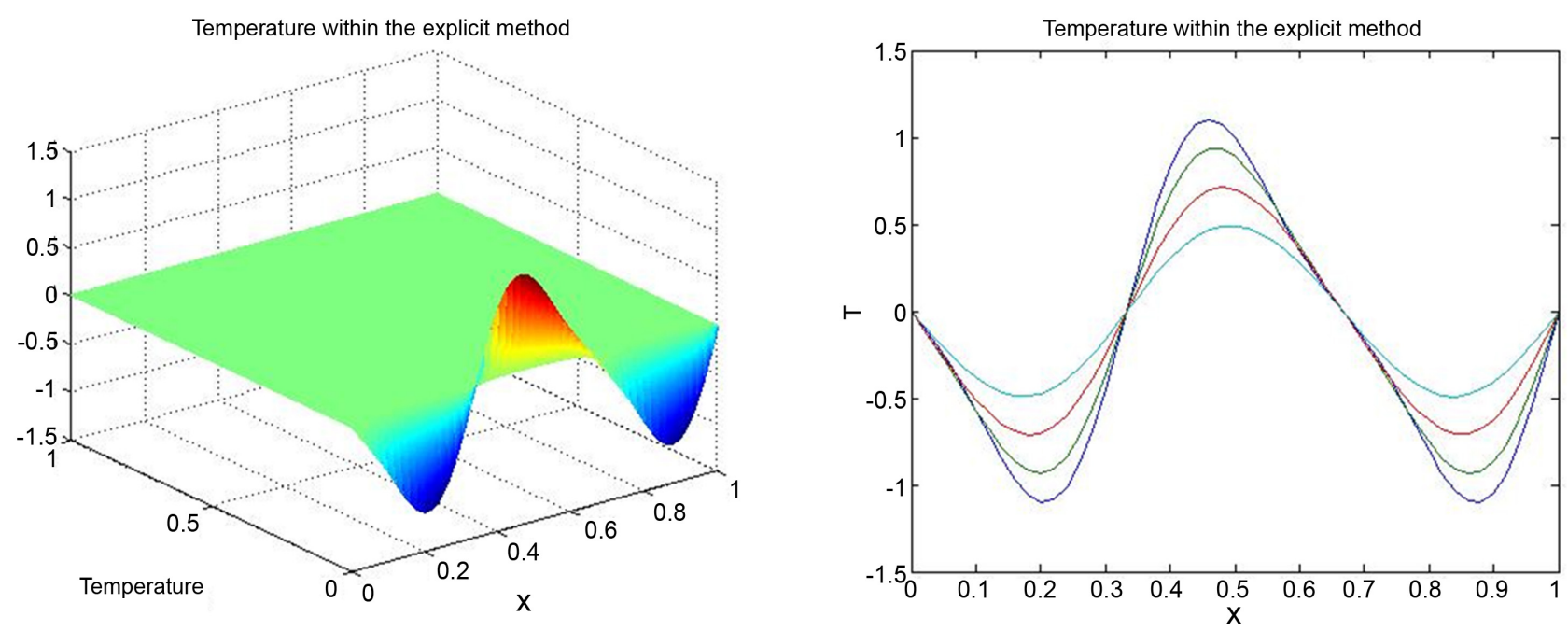

Figure 4. Temperature distributions at several times for the heat conduction of the Copper for example 4.
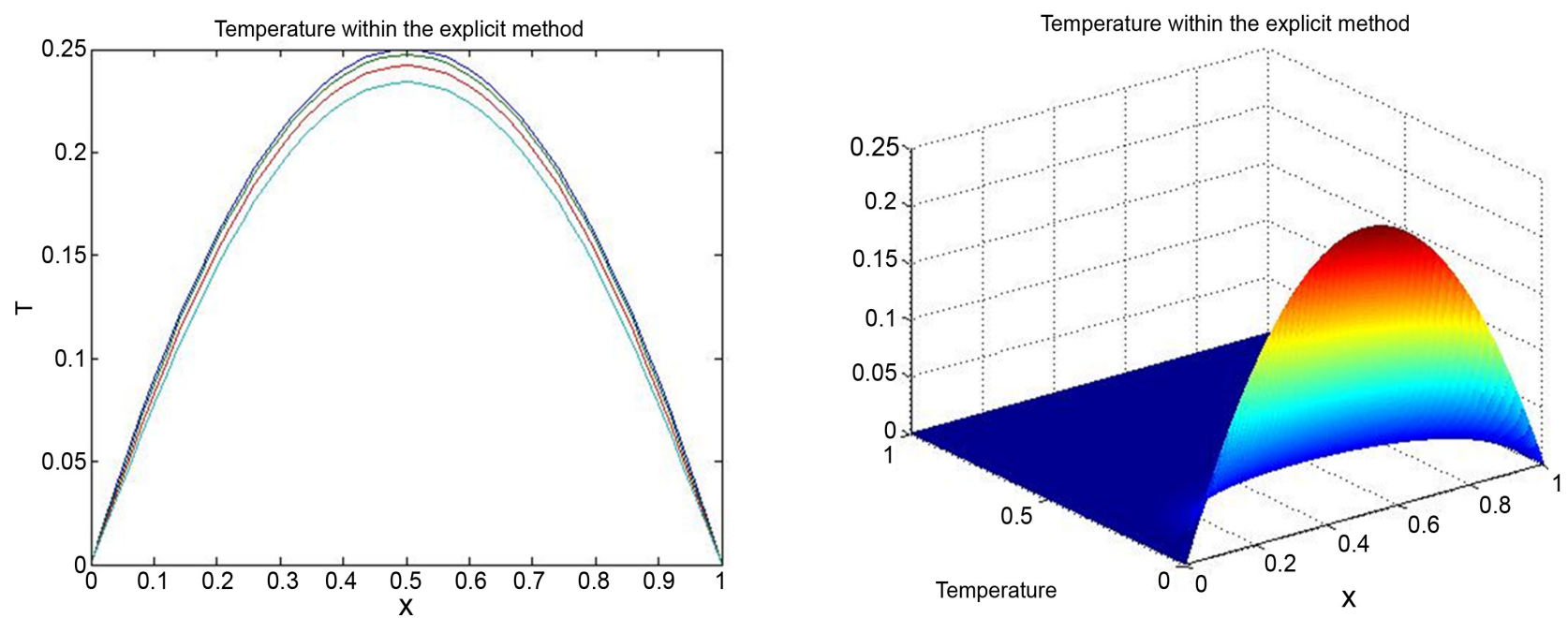

Figure 5. Temperature distributions at several times for the heat conduction of the Copper for example 5.
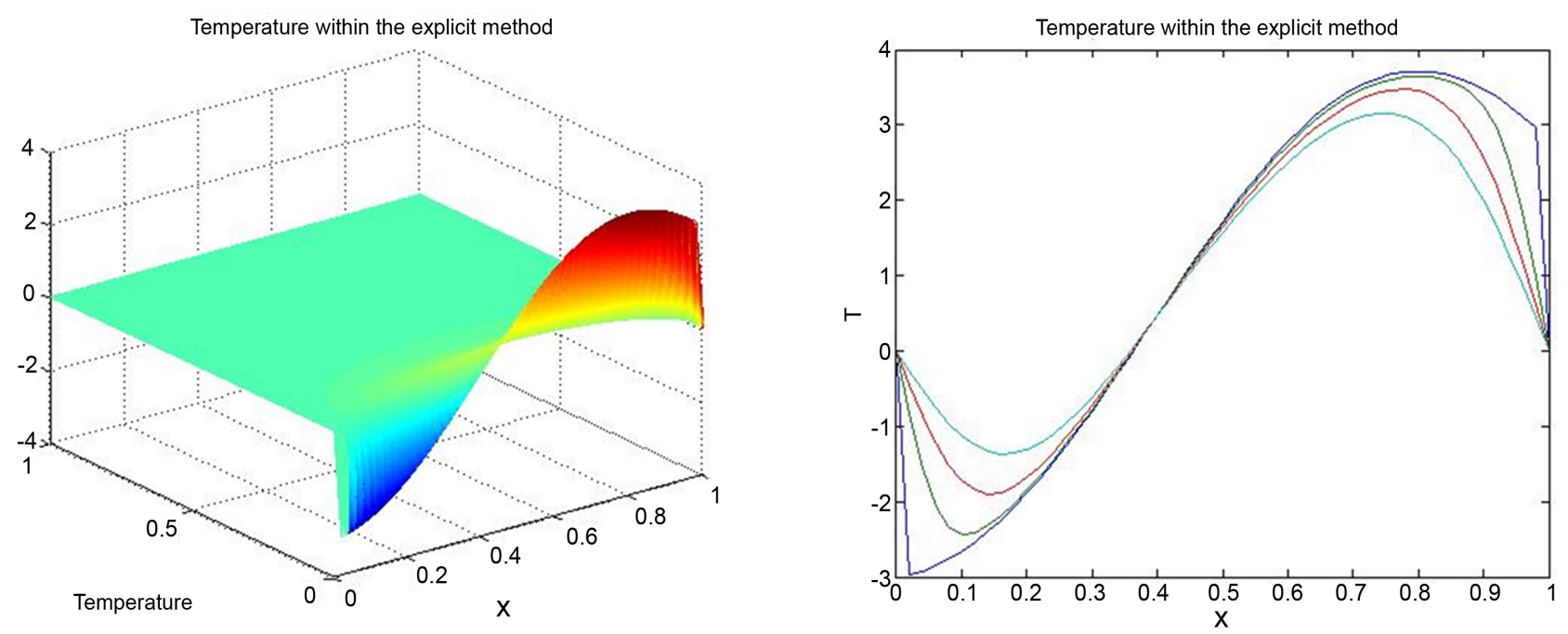

Figure 6. Temperature distributions at several times for the heat conduction of the Copper for example 6. 

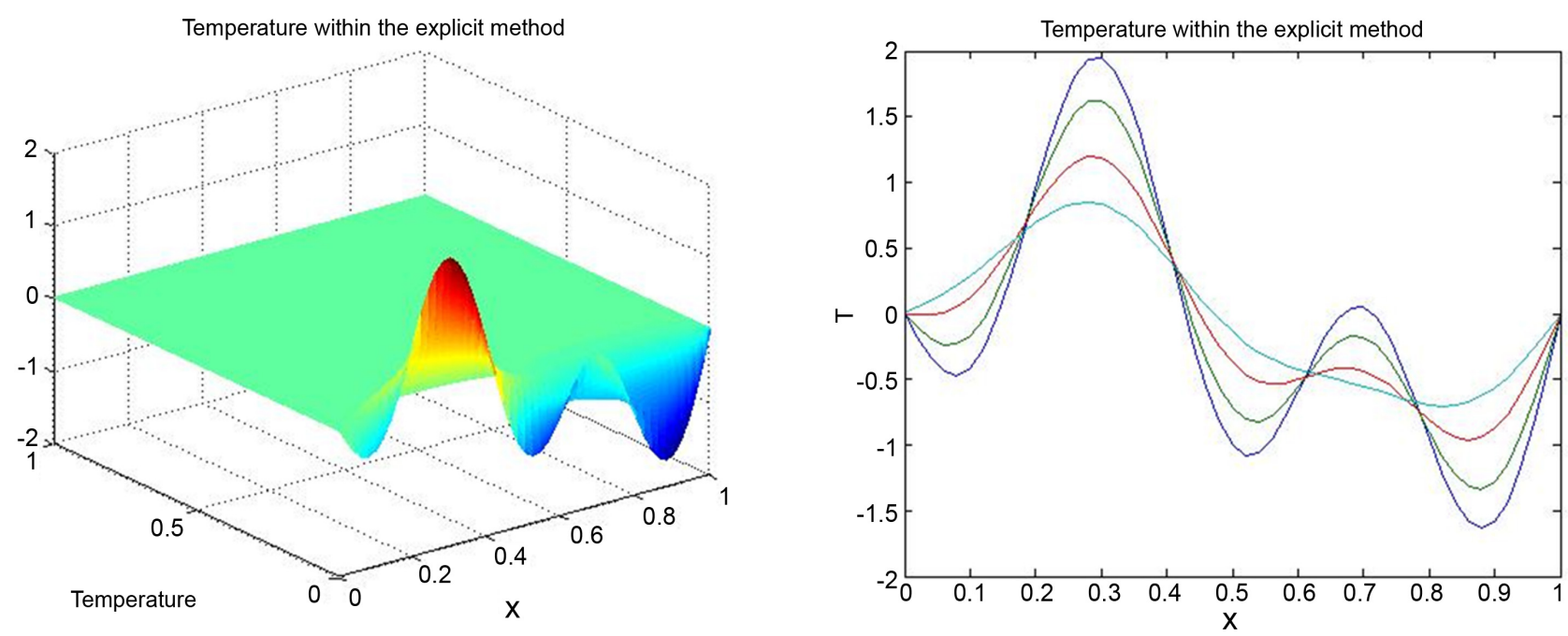

Figure 7. Temperature distributions at several times for the heat conduction of the Copper for example 7.
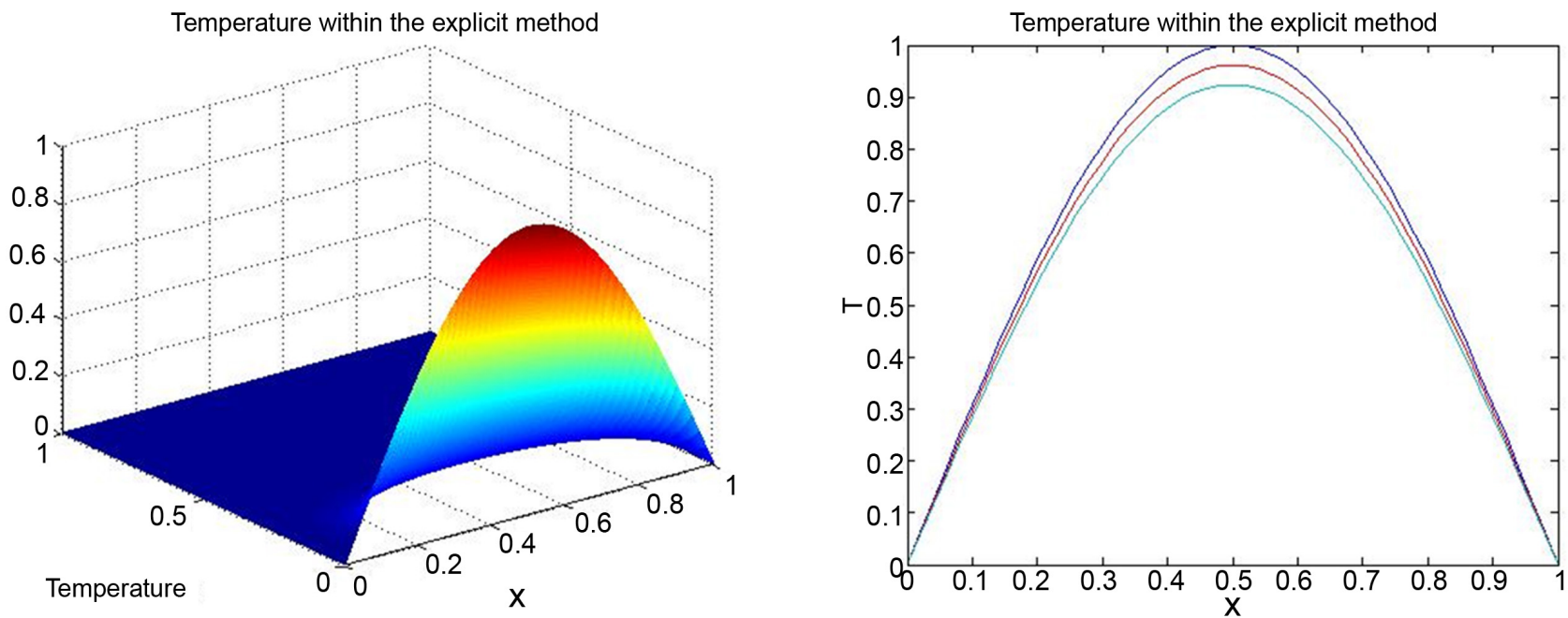

Figure 8. Temperature distributions at several times for the heat conduction of the Copper for example 8.
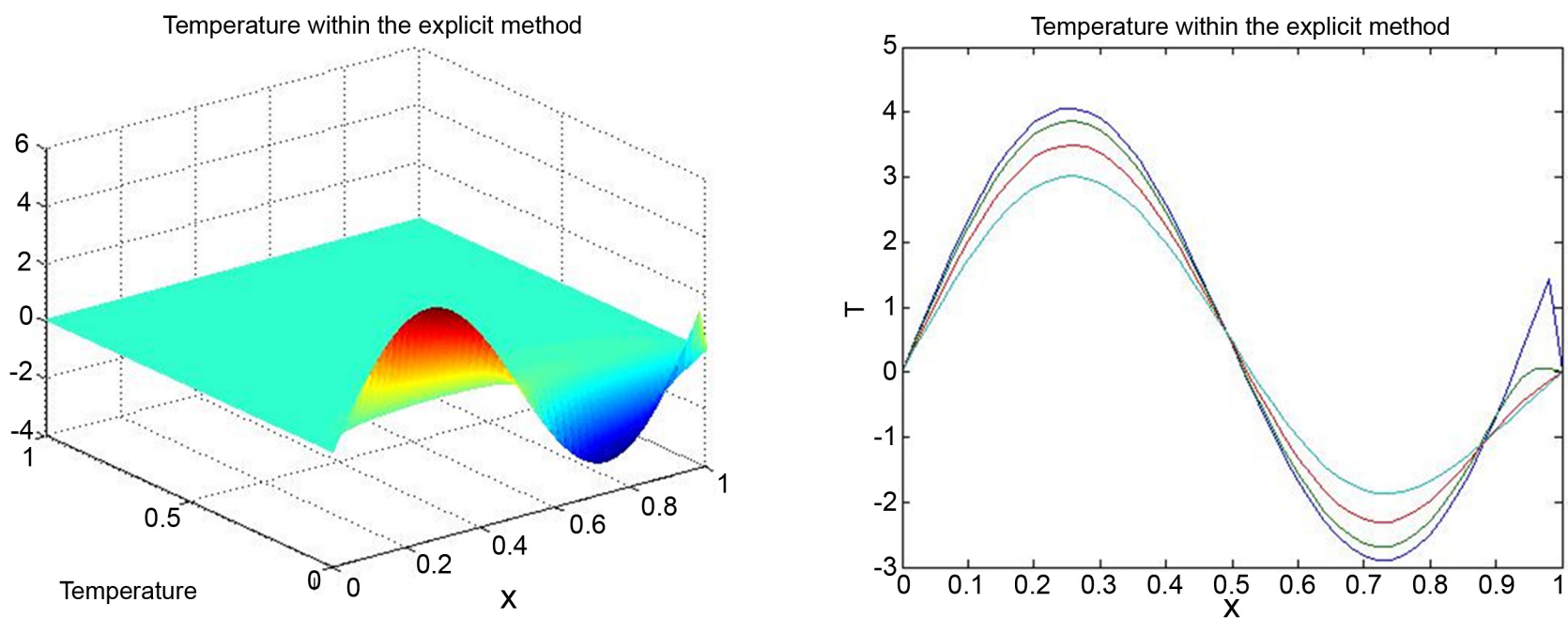

Figure 9. Temperature distributions at several times for the heat conduction of the Copper for example 9. 


$$
u(0, t)=u(1, t)=0, t>0 ; u(x, 0)=40-3 x, 0 \leq x \leq 1 .
$$

Figure 2 shows the temperature distribution of the copper conduction of the conditions

$$
u(0, t)=u(1, t)=0, t>0 ; u(x, 0)=7 \cos \left(\frac{5}{2} x\right), 0 \leq x \leq 1 .
$$

Figure 3 shows the temperature distribution of the copper conduction of the conditions

$$
u(0, t)=u(1, t)=0, t>0 ; u(x, 0)=1+\cos (2 \pi x), 0 \leq x \leq 1 .
$$

Figure 4 shows the temperature distribution of the copper conduction of the conditions

$$
\begin{aligned}
& u(0, t)=u(1, t)=0, t>0 \\
& u(x, 0)=-\sin (3 \pi x)+\frac{1}{4} \sin (6 \pi x), 0 \leq x \leq 1 .
\end{aligned}
$$

Figure 5 shows the temperature distribution of the copper conduction of the conditions

$$
u(0, t)=u(1, t)=0, t>0 ; u(x, 0)=x(1-x), 0 \leq x \leq 1
$$

Figure 6 shows the temperature distribution of the copper conduction of the conditions

$$
u(0, t)=u(1, t)=0, t>0 ; u(x, 0)=\sin x-3 \cos 4 x, 0 \leq x \leq 1 .
$$

Figure 7 shows the temperature distribution of the copper conduction of the conditions

$$
u(0, t)=u(1, t)=0, t>0 ; u(x, 0)=\sin 2 \pi x-\sin 5 \pi x, 0 \leq x \leq 1 .
$$

Figure 8 shows the temperature distribution of the copper conduction of the conditions

$$
u(0, t)=u(1, t)=0, t>0 ; u(x, 0)=\sin \pi x, 0 \leq x \leq 1 .
$$

Figure 9 shows the temperature distribution of the copper conduction of the conditions

$$
\begin{aligned}
& u(0, t)=u(1, t)=0, t>0 ; \\
& u(x, 0)=2 \sin (\pi x / 2)-\sin \pi x+4 \sin 2 \pi x, 0 \leq x \leq 1 .
\end{aligned}
$$

\section{Conclusion}

In this paper, the calculations were performed by the MATLAB program for the programming and the corresponding evolutionary laws on the basis of the onedimensional mathematical model of one-dimensional thermal conductivity using the Finite differences method of solving the heat-conduction equation of Copper. A numerical example has shown the effectiveness of the proposed method. In addition, it should be noted that the method used is easy and flexible in finding solutions. This work focuses on copper because, it is the high electrical conductivity of this metal, which comes second-after silver-in the list of the 
most conductive minerals, its abundance in nature and its low cost, in addition to being a mineral that has antimicrobial properties, which reduces the bacterial burden of surfaces and bodies, all of which are considered to be the advantages that I nominated to be a mineral used in many areas of daily life.

\section{Acknowledgements}

This paper was supported by the Deanship of Scientific Research (DSR), King Abdulaziz University, Jeddah.

\section{Conflicts of Interest}

The authors declare no conflicts of interest regarding the publication of this paper.

\section{References}

[1] William, F.A. (1992) Numerical Methods for Partial Differential Equations. 3rd Edition, Academic Press, New York.

[2] Douglas, J. and Rachford, H.H. (1956) On the Numerical Solution of Heat Conduction Problems in Two and Three Space Variables. Transactions of the American Mathematical Society, 82, 421-439.

https://doi.org/10.1090/S0002-9947-1956-0084194-4

[3] Mitchell, A.R. and Griffiths, D.F. (1980) The Finite Difference Method in Partial Differential Equations. John Wiley \& Sons, Chichester.

[4] Dalal, A.M, Amani, Z.B. and Badreeh, M.G. (2014) Numerical Solution of Volterra Integral Equation of Second Kind Using Implicit Trapezoidal. Journal of Advances in Mathematics, 8, 1540-1553.

[5] Dalal, A.M. (2014) Adomian Decomposition Method of Fredholm Integral Equation of the Second Kind Using Maple. Journal of Advances in Mathematics, 9, 1868-1875.

[6] Dalal, A.M. (2014) Application of Adomian Decomposition Method for Solving of Fredholm Integral Equation of the Second Kind. European Journal of Science and Engineering, 9, 1-9.

[7] Dalal, A.M. (2016) Adomian Decomposition Method for Solving of Fredholm Integral Equation of the Second Kind Using Matlab. International Journal of GEOMATE, 11, 2830-2833.

[8] Dalal, A.M. and Honida, M.M. (2018) Numerical Solution of System of Three Nonlinear Volterra Integral Equation Using Implicit Trapezoidal. Journal of Mathematics Research, 10, 44. https://doi.org/10.5539/jmr.v10n1p44

[9] Dalal, A.M., Amal, I.A. and Eman, S.A. (2019) Finite Difference Method for Solving Heat Conduction Equation of The Granite. International Journal of GEOMATE, 17, 135-140. https://doi.org/10.21660/2019.61.8172

[10] Dalal, A.M. (2020) Finite Difference Method for Solving Heat Conduction Equation of The Brick. International Journal of GEOMATE, 18, 114-119.

https://doi.org/10.21660/2020.68.9168 